\title{
Organochlorine Pesticides Quantification in Smoke-Dried Fish Samples and Extrapolative Toxicity Effect in Rabbit Samples
}

\author{
Nuntah, $\mathrm{JN}^{1 *}$, Abolagba $\mathrm{OJ}^{1}$, Igene $\mathrm{JO}^{2}$, Usifoh $\mathrm{SF}^{3}$, Omoti $\mathrm{CE}^{4}$ and Usifoh $\mathrm{CO}^{5}$ \\ ${ }^{1}$ Department of Aquaculture and Fisheries Management, ${ }^{2}$ Department of Food Science Technology, ${ }^{3}$ Department of \\ Clinical Pharmacy and Pharmacy Practice, ${ }^{4}$ Department of Haematology, ${ }^{5}$ Department of Pharmaceutical Chemistry, \\ University of Benin, Benin City, Nigeria
}

\section{*Corresponding Author}

Nuntah Joseph Nkem

\author{
Article History \\ Received: 18.06 .2020 \\ Accepted: 25.06 .2020 \\ Published: 30.06 .2020
}

\begin{abstract}
Smoke-dried fish mongers and marketers have adopted the use of organochlorines (OCPs) in the preservation of smoke-dried fish especially during storage. Although the OCPs laden fishes appear free from insect infestation, the retained residual concentrations in the fish flesh upon consumption possibly causes harm since OCPs can absorb and bio-accumulate in the blood stream and fatty tissues. This study therefore seek to quantify the residual concentrations of OCPs (DDT, endosulfan and lindane) in smoke-dried fish samples and extrapolate their toxicity effects in rabbit samples. The smoke-dried fishes were purchased from vendors, extracted and analyzed using the GCMS for OCPs (DDT, endosulfan and lindane). Thirty rabbit samples $(1000 \mathrm{~g}-1200 \mathrm{~g})$ were divided into four groups (3 rabbits [control] and 9 rabbits each for DDT, endosulfan and lindane treatment groups) and three (3) concentration levels $\left(\mathrm{LD}_{50}\right.$; $1 / 2$ of $\mathrm{LD}_{50}\left[\mathrm{LD}_{25}\right]$ and $1 / 4$ of $\left.\mathrm{LD}_{50}\left[\mathrm{LD}_{12.5}\right]\right)$ were determined based on the rabbit's body weight and established OCPs $\mathrm{LD}_{50}$ values, then subcutaneously administered to the rabbits as a single dose. The OCPs toxicity effects on exposed rabbits were determined by analyzing the blood parameters (heamatology and serum biochemistry assay) at exposure periods ( 1 , 3 and 7 days). The OCPs exposed rabbits exhibited varied clinical signs (itching, restlessness, jerky movements, skin scratching, salivation, increased urination and nervous signs) and their blood parameters count were significantly different $(\mathrm{P}<0.05)$ compared to the control (non-OCPs treated) rabbits. OCPs toxicity constitute real threat to public health considering their severe detrimental effects on the blood parameters of exposed rabbits, thus compromising their immune system and possibly leading to varied health complications. Therefore, public sensitization especially to fish mongers and marketers on the dangers of OCPs and the need to shun their use in smoke-dried fish preservation should be intensified and sustained.
\end{abstract}

Keywords: Organochlorine, Quantification, Smoke-dried, Toxicity, Rabbit.

\section{INTRODUCTION}

Smoke-dried fish are subjected to losses due to spoilage when not adequately preserved or stored and such losses arise from the combined effect of insects and other biological agents that flourish under tropical hot and humid conditions [1]. Some fish mongers and marketers have adopted the use of pesticides to preserve smoke-dried fish during the channels of packaging, storage and distribution in order to eliminate and halt insect infestation, thereby limiting economic losses on the fish mongers [2-4]. The class organochlorine pesticides (OCPs) have been the most detected pesticides in preserved smoke-dried fish due to their cheap cost and efficacy to combat insect infestations [5, 6]. OCPs are classified Persistent Organic Pollutants (POPs) because they remain in the environment for decades following their use and can travel long distances from source through atmospheric or aqueous transport, then accumulate in fatty tissues of exposed organisms with varieties of toxic endpoints [7]. Studies have shown that OCPs exposures have detrimental health implications on the environment, wildlife and human [8] and the OCPs (DDT, endosulfan and lindane) were the most detected pesticides used in smoke-dried fish samples preservation [3]. Although the OCPs laden fishes appear free from insect infestation there are however, retained residual concentrations in the fish flesh and tissues that can possibly cause harm to animals and human health upon consumption, since OCPs are known to absorb and bio-accumulate in the

Copyright @ 2020: This is an open-access article distributed under the terms of the Creative Commons Attribution license which permits unrestricted use, distribution, and reproduction in any medium for non commercial use (NonCommercial, or CC-BY-NC) provided the original author and source are credited. 
blood stream and fatty tissues of animals and humans and their prolonged exposures exerts systemic, immunologic, teratogenic, and carcinogenic effects [9]. OCPs have resulted in a wide range of adverse effects evident in worldwide deaths and chronic diseases such as reproductive failure, immune system malfunction, endocrine disruptions, hypertension, cardiovascular disorders and cancers [10, 11]. This study therefore seek to quantify the residual concentrations of OCPs (DDT, endosulfan and lindane) in smoke-dried fish samples and extrapolate their toxicity effects in exposed rabbit samples.

\section{Materials ANd Methods}

\section{Collection and extraction of the smoke-dried fish samples}

Smoke-dried fish samples were randomly purchased from vendors and taken to University of Benin Pesticide Research Laboratory (UBPRL). The fish samples were pulverized and $20 \mathrm{~g}$ of each ground sample placed in a thimble and extracted using dichloromethane solvent in a Soxhlet apparatus. The extracts were dried over anhydrous sodium sulphate, concentrated to about $2 \mathrm{ml}$ under pure stream nitrogen at $40^{\circ} \mathrm{C}$, cleaned and reconstituted to $1 \mathrm{ml}$ in dichloromethane [12]. The GC-MS-QP 2010 SE Shimadzu, (JAPAN), equipped with an electron capture detector was used to analyze and quantify the OCPs (DDT, endosulfan and lindane) in the smoke-dried fish samples.

\section{Animal Experimental Study}

Forty (40) male rabbits weighing about $1 \mathrm{~kg}$ each were purchased and transported to the Rabbit Unit, University of Benin Teaching and Research Farm. The rabbits were housed individually in raised hutches, provided prophylaxis treatment, fed ad-libitum and allowed to acclimatize for two weeks. Thirty (30) of the apparently healthy rabbits (1000 g - $1200 \mathrm{~g}$ ) were divided into four groups (3 rabbit samples [control]; 9 rabbit samples each for DDT, endosulfan and lindane groups). Based on OCPs (DDT, endosulfan and lindane) established $\mathrm{LD}_{50}$ values and body weight of the rabbit samples, 3 treatment levels $\left(\mathrm{LD}_{50} ; 1 / 2\right.$ of $\mathrm{LD}_{50}\left[\mathrm{LD}_{25}\right]$ and $1 / 4$ of $\mathrm{LD}_{50}\left[\mathrm{LD}_{12.5}\right]$ ) were determined and administered subcutaneously to the rabbit as a single dose and the OCPs toxicity effect on the exposed rabbit blood parameters (heamatology and serum biochemical) were determined at 1,3 and 7 days exposure period.

\section{Collection and Analysis of the Rabbit Blood samples}

Blood samples were collected from the medial peripheral vein of rabbit ear by venepuncture and slowly expressed into Ethylene Diamine Tetra Acetic Acid (EDTA), anticoagulant tubes for haematological analysis, floride oxalate tubes for glucose estimation and plain tubes for other serum biochemical assays [13]. The automated three parts differential full blood count machine (Mythic $22 \mathrm{CT}$ ) was used for analysis of the haematological parameters (White blood cells count [WBC], Red blood cells count [RBC], Haemoglobin concentration [HC], Packed cell volume [PCV], Differential white blood cell count, Red blood cell indices, Platelets count [PC], Mean Corpuscular Haemoglobin [MCH], Mean Corpuscular Haemoglobin Concentration [MCHC], Mean Corpuscular Volume [MCV], Mean Platelet Volume [MPV], Red cell Distribution Width [RDW] and Platelet Distribution Width [PDW]). The blood serum assays (renal function, liver function, protein, fasting blood sugar, and uric acid test) were analyzed using the PRIETEST EASYLAB biochemical analyzer.

\section{Statistical Analysis}

Detected OCPs in the smoke-dried fish samples were laid in a completely randomized design (CRD) and replicated three (3) times in a one-way analysis of variance (ANOVA). The OCPs toxicity effects on the exposed rabbit blood parameters were laid out in 3x3 factorial arrangement in a completely randomized design (CRD), replicated three times in a two-way analysis of variance (ANOVA). The arising means were separated by Duncan multiple range test, using Genstat $12^{\text {th }}$ edition statistical package [14].

\section{ReSUlTS}

\section{Physical observations of the OCPs Exposed Rabbits}

The exposed rabbit samples subcutaneously injected OCPs (DDT, lindane and endosulfan) exhibited varied clinical signs such as itching, restlessness, jerky movements, skin scratching, salivation, increased urination and nervous signs (ataxia, staggering gait and dizziness). The clinical signs were dose dependent and the effects persisted between 10 to 30 minutes. Endosulfan exposed rabbits exhibited severe signs of nervous disorders than the DDT and lindane exposed rabbit samples.

\section{Haematological Samples}

Tables 1 - 9 show OCPs toxicity effects on exposed rabbit samples haematology based on injected dose, exposure periods and their interactions (injected dose and exposure periods). The OCPs (DDT, lindane and endosulfan) toxicity resulted in significant deviations $(\mathrm{P}<0.05)$ in the haematological range indices of exposed rabbit samples compared to non-OCPs exposed rabbit samples (control). The OCPs exposed rabbits counts reduced significantly 
$(\mathrm{P}<0.05)$ in white blood cell $(2.17$ - 4.40), red blood cell $(4.71$ - 4.94), haemoglobin $(10.63$ - 11.83), haematocrit $(29.40$ 31.70), mean corpuscular haemoglobin (20.14 - 23.93), platelet counts (115.7 - 269.0), plateletcrit (0.05 - 0.17), mean platelet volume $(3.70$ - 5.12) and platelet distribution width $(3.17$ - 5.70). While the monocytes $(0.43$ - 0.56$)$, granulocytes $(0.37$ - 1.77), mean corpuscular volume $(67.20$ - 74.33) and mean corpuscular haemoglobin concentration $(35.50$ - 40.11) increased significantly $(\mathrm{P}<0.05)$ in counts. The OCPs exposed rabbit samples decreased in haematological counts with increase in the exposure periods (1, 3 and 7 days) but these were not significantly different $(\mathrm{P}>0.05)$. The interactions between the OCPs (DDT, lindane and endosulfan) and exposure periods (1, 3 and 7 days) resulted in significant decrease $(\mathrm{P}<0.05)$ in heamatological parameters with increase in injected doses and exposure time.

Table-1: Effect of DDT on Rabbit Haematology

\begin{tabular}{|c|c|c|c|c|c|}
\hline Parameters & & Injecte & lume (1 & & \pm SEM \\
\hline & $\mathbf{0}$ & 0.38 & 0.75 & 1.50 & \\
\hline White blood cell $\left(\times 10^{3} \mu \mathrm{l}\right)$ & $6.10^{\mathrm{a}}$ & $4.40^{\mathrm{b}}$ & $3.13^{\mathrm{c}}$ & $2.17^{\mathrm{d}}$ & 0.33 \\
\hline Lymphocytes $\left(\mathrm{x} 10^{3} \mu \mathrm{l}\right)$ & $5.10^{\mathrm{a}}$ & $1.80^{\mathrm{b}}$ & $1.53^{\mathrm{b}}$ & $1.30^{\mathrm{b}}$ & 0.33 \\
\hline Monocytes $\left(x 10^{3} \mu 1\right)$ & $0.40^{\mathrm{b}}$ & $0.43^{\mathrm{a}}$ & $0.47^{\mathrm{a}}$ & $0.49^{\mathrm{a}}$ & 0.06 \\
\hline $\operatorname{Gr}\left(\times 10^{3} \mu 1\right)$ & $0.60^{\mathrm{c}}$ & $0.74^{\mathrm{b}}$ & $1.30^{\mathrm{ab}}$ & $1.77^{\mathrm{a}}$ & 0.28 \\
\hline Lymphocytes (\%) & $83.40^{\mathrm{a}}$ & $70.50^{\mathrm{a}}$ & $44.50^{\mathrm{b}}$ & $35.07^{\mathrm{b}}$ & 9.16 \\
\hline Monocytes (\%) & $7.10^{\mathrm{c}}$ & $8.60^{\mathrm{c}}$ & $12.90^{\mathrm{b}}$ & $18.67^{\mathrm{a}}$ & 1.12 \\
\hline $\operatorname{Gr}(\%)$ & $9.50^{\mathrm{c}}$ & $23.77^{\mathrm{b}}$ & $43.70^{\mathrm{a}}$ & $49.00^{\mathrm{a}}$ & 7.33 \\
\hline Red blood cell $\left(\times 10^{-6} \mu \mathrm{l}\right)$ & $6.14^{\mathrm{a}}$ & $4.94^{\mathrm{b}}$ & $4.81^{\mathrm{b}}$ & $4.71^{\mathrm{b}}$ & 0.17 \\
\hline Heamoglobin $(\mathrm{g} / \mathrm{dL})$ & $14.40^{\mathrm{a}}$ & $11.83^{\mathrm{b}}$ & $11.40^{\mathrm{b}}$ & $10.63^{\mathrm{c}}$ & 0.27 \\
\hline HCT (\%) & $40.70^{\mathrm{a}}$ & $31.70^{b}$ & $30.53^{\mathrm{b}}$ & $29.40^{\mathrm{b}}$ & 1.35 \\
\hline Mean corpuscular volume (fl) & $66.20^{\mathrm{b}}$ & $67.56^{\mathrm{a}}$ & $68.97^{\mathrm{a}}$ & $74.33^{\mathrm{a}}$ & 0.83 \\
\hline Mean corpuscular haemoglobin (pg) & $23.40^{\mathrm{a}}$ & $23.93^{\mathrm{a}}$ & $23.73^{\mathrm{a}}$ & $23.83^{\mathrm{a}}$ & 1.01 \\
\hline Mean corpuscular heamoglobin concentration $(\mathrm{g} / \mathrm{dl})$ & $35.30^{\mathrm{b}}$ & $35.50^{\mathrm{b}}$ & $35.73^{\mathrm{b}}$ & $40.11^{\mathrm{a}}$ & 1.39 \\
\hline RDW (\%) & $18.20^{\mathrm{a}}$ & $17.98^{\mathrm{b}}$ & $17.87^{\mathrm{b}}$ & $17.77^{\mathrm{b}}$ & 0.12 \\
\hline Platelet count $\left(\times 10^{3} \mu\right)$ & $358.0^{\mathrm{a}}$ & $225.3^{\mathrm{b}}$ & $125.3^{\mathrm{c}}$ & $115.7^{\mathrm{d}}$ & 12.8 \\
\hline PCT $(\%)$ & $0.19^{\mathrm{a}}$ & $0.13^{\mathrm{b}}$ & $0.07^{\mathrm{c}}$ & $0.07^{\mathrm{c}}$ & 0.01 \\
\hline MPV (fl) & $5.20^{\mathrm{c}}$ & $4.83^{\mathrm{b}}$ & $4.87^{\mathrm{b}}$ & $4.47^{\mathrm{a}}$ & 0.11 \\
\hline PDW (fl) & $6.60^{\mathrm{a}}$ & $5.70^{\mathrm{a}}$ & $5.69^{\mathrm{a}}$ & $5.93^{\mathrm{b}}$ & 0.07 \\
\hline
\end{tabular}

Table-2: Effect of DDT on the Exposure Periods

\begin{tabular}{|c|c|c|c|c|}
\hline Parameters & & osure $\mathbf{T}$ & & \pm SEM \\
\hline & 1 day & 3 days & 7 days & \\
\hline White blood cell $\left(\times 10^{3} \mu \mathrm{l}\right)$ & $4.04^{\mathrm{a}}$ & $3.94^{\mathrm{a}}$ & $3.87^{\mathrm{a}}$ & 0.29 \\
\hline Lymphocytes $\left(\mathrm{x} 10^{3} \mu \mathrm{l}\right)$ & $2.60^{\mathrm{a}}$ & $2.48^{\mathrm{a}}$ & $2.37^{\mathrm{a}}$ & 0.28 \\
\hline Monocytes $\left(x 10^{3} \mu 1\right)$ & $0.51^{\mathrm{a}}$ & $0.44^{\mathrm{a}}$ & $0.39^{\mathrm{a}}$ & 0.06 \\
\hline $\operatorname{Gr}\left(\times 10^{3} \mu \mathrm{l}\right)$ & $1.21^{\mathrm{a}}$ & $1.10^{\mathrm{a}}$ & $0.99^{\mathrm{a}}$ & 0.24 \\
\hline Lymphocytes (\%) & $8.96^{\mathrm{a}}$ & $58.37^{\mathrm{a}}$ & $57.78^{\mathrm{a}}$ & 7.93 \\
\hline Monocytes (\%) & $11.99^{\mathrm{a}}$ & $11.82^{\mathrm{a}}$ & $11.64^{\mathrm{a}}$ & 0.97 \\
\hline $\mathrm{Gr}(\%)$ & $31.73^{\mathrm{a}}$ & $31.49^{\mathrm{a}}$ & $31.25^{\mathrm{a}}$ & 6.35 \\
\hline Red blood cell $\left(\times 10^{-6} \mu \mathrm{l}\right)$ & $5.20^{\mathrm{a}}$ & $5.15^{\mathrm{a}}$ & $5.09^{\mathrm{a}}$ & 0.15 \\
\hline Heamoglobin $(\mathrm{g} / \mathrm{dL})$ & $12.23^{\mathrm{a}}$ & $12.06^{\mathrm{a}}$ & $11.83^{\mathrm{a}}$ & 0.23 \\
\hline $\mathrm{HCT}(\%)$ & $33.34^{\mathrm{a}}$ & $33.07 \mathrm{a}$ & $32.84^{\mathrm{a}}$ & 1.17 \\
\hline Mean corpuscular volume (fl) & $67.97^{\mathrm{a}}$ & $68.52^{\mathrm{a}}$ & $68.66^{\mathrm{a}}$ & 1.59 \\
\hline Mean corpuscular haemoglobin (pg) & $23.45^{\mathrm{a}}$ & $23.27^{\mathrm{a}}$ & $23.10^{\mathrm{a}}$ & 0.87 \\
\hline Mean corpuscular heamoglobin concentration $(\mathrm{g} / \mathrm{dl})$ & $36.45^{\mathrm{a}}$ & $36.15^{\mathrm{a}}$ & $35.88^{\mathrm{a}}$ & 1.21 \\
\hline RDW (\%) & $18.32^{\mathrm{a}}$ & $18.17^{\mathrm{a}}$ & $18.07^{\mathrm{a}}$ & 0.10 \\
\hline Platelet count $\left(\mathrm{x} 10^{3} \mu\right)$ & $231.0^{\mathrm{a}}$ & $212.5^{\mathrm{b}}$ & $195.0^{\mathrm{c}}$ & 1.10 \\
\hline PCT $(\%)$ & $0.13^{\mathrm{a}}$ & $0.12^{\mathrm{b}}$ & $0.10^{\mathrm{c}}$ & 0.001 \\
\hline MPV (fl) & $6.18^{\mathrm{a}}$ & $5.83^{\mathrm{b}}$ & $5.53^{\mathrm{c}}$ & 0.09 \\
\hline PDW (fl) & $6.97^{\mathrm{a}}$ & $6.08^{\mathrm{b}}$ & $5.65^{\mathrm{c}}$ & 0.06 \\
\hline
\end{tabular}

${ }^{\mathrm{a}}=$ Means in a row with similar superscripts are not significantly different $(\mathrm{P}<0.05)$ 
Table-3: Effect of DDT on Interaction (injected dose $x$ exposure periods)

\begin{tabular}{|c|c|c|c|c|c|c|c|c|c|c|}
\hline \multirow[t]{2}{*}{ Concentration } & \multirow{2}{*}{$\begin{array}{l}\text { Exposure } \\
\text { Time }\end{array}$} & \multicolumn{9}{|c|}{ Parameters } \\
\hline & & WBC & LYM & MON & GR & $\begin{array}{c}\text { LYM } \\
(\%)\end{array}$ & $\begin{array}{c}\text { MON } \\
(\%)\end{array}$ & GR & RBC & HEA \\
\hline$M$ & 0 hour & $6.10^{\mathrm{a}}$ & $5.30^{\mathrm{a}}$ & $0.40^{\text {cd }}$ & $0.60^{\mathrm{a}}$ & $83.40^{\mathrm{a}}$ & $7.10^{\mathrm{b}}$ & $9.50^{\mathrm{a}}$ & $6.140^{\mathrm{a}}$ & $14.40^{\mathrm{a}}$ \\
\hline \multirow[t]{3}{*}{ M1 } & 1 day & $4.53^{\mathrm{abc}}$ & $1.97^{\mathrm{b}}$ & $0.90^{\mathrm{a}}$ & $2.00^{\mathrm{a}}$ & $72.50^{\mathrm{a}}$ & $18.93^{\mathrm{a}}$ & $49.20^{\mathrm{a}}$ & $4.963^{\mathrm{b}}$ & $12.27^{\mathrm{b}}$ \\
\hline & 3 days & $4.37^{\mathrm{abc}}$ & $1.80^{\mathrm{b}}$ & $0.77^{\mathrm{ab}}$ & $1.77^{\mathrm{a}}$ & $70.50^{\mathrm{a}}$ & $18.67^{\mathrm{a}}$ & $49.00^{\mathrm{a}}$ & $4.943^{b}$ & $11.83^{\mathrm{bc}}$ \\
\hline & 7 days & $4.30^{\mathrm{bc}}$ & $1.63^{b}$ & $0.70^{\mathrm{abc}}$ & $1.53^{\mathrm{a}}$ & $68.50^{\mathrm{a}}$ & $18.40^{\mathrm{a}}$ & $48.80^{\mathrm{a}}$ & $4.923^{b}$ & $11.40^{\mathrm{bc}}$ \\
\hline \multirow[t]{3}{*}{ M2 } & 1 day & $3.23^{\mathrm{cd}}$ & $1.70^{\mathrm{b}}$ & $0.57^{\mathrm{abc}}$ & $1.40^{\mathrm{a}}$ & $44.67^{\mathrm{a}}$ & $13.03^{\mathrm{ab}}$ & $44.13^{\mathrm{a}}$ & $4.970^{b}$ & $11.47^{\mathrm{bc}}$ \\
\hline & 3 days & $3.13^{\mathrm{cd}}$ & $1.53^{b}$ & $0.47^{\mathrm{bcd}}$ & $1.30^{\mathrm{a}}$ & $44.50^{\mathrm{a}}$ & $12.90^{\mathrm{ab}}$ & $43.70^{\mathrm{a}}$ & $4.810^{b}$ & $11.37^{\mathrm{bc}}$ \\
\hline & 7 days & $3.03^{\mathrm{cd}}$ & $1.37^{\mathrm{b}}$ & $0.37^{\mathrm{cd}}$ & $1.20^{\mathrm{a}}$ & $44.33^{\mathrm{a}}$ & $12.77^{\mathrm{ab}}$ & $43.27^{\mathrm{a}}$ & $4.650^{b}$ & $11.07^{\mathrm{bc}}$ \\
\hline \multirow[t]{3}{*}{ M3 } & 1 day & $2.30^{\mathrm{d}}$ & $1.43^{\mathrm{b}}$ & $0.17^{d}$ & $0.83^{\mathrm{a}}$ & $35.27^{\mathrm{a}}$ & $8.90^{\mathrm{b}}$ & $24.10^{\mathrm{a}}$ & $4.743^{b}$ & $10.80^{\mathrm{bc}}$ \\
\hline & 3 days & $2.17^{\mathrm{d}}$ & $1.30^{\mathrm{b}}$ & $0.13^{\mathrm{d}}$ & $0.73^{\mathrm{a}}$ & $35.07^{\mathrm{a}}$ & $8.60^{b}$ & $23.77^{\mathrm{a}}$ & $4.713^{b}$ & $10.63^{\mathrm{c}}$ \\
\hline & 7 days & $2.03^{\mathrm{d}}$ & $1.17^{\mathrm{b}}$ & $0.10^{\mathrm{d}}$ & $0.63^{\mathrm{a}}$ & $34.87^{\mathrm{a}}$ & $8.30^{b}$ & $23.43^{\mathrm{a}}$ & $4.683^{b}$ & $10.47^{\mathrm{c}}$ \\
\hline$\pm \mathrm{SEM}$ & & 0.57 & 0.57 & 0.11 & 0.49 & 15.86 & 1.943 & 12.70 & 0.2955 & 0.472 \\
\hline
\end{tabular}

Table-3: Continued

\begin{tabular}{|c|c|c|c|c|c|c|c|c|c|c|}
\hline \multirow[t]{2}{*}{ Concentration } & \multirow{2}{*}{$\begin{array}{l}\text { Exposure } \\
\text { Time }\end{array}$} & \multicolumn{9}{|c|}{ Parameters } \\
\hline & & HCT & MCV & МСH & МСНС & RDW & PC & PCT & MPV & PDW \\
\hline $\mathrm{M}$ & 0 hour & $40.70^{\mathrm{a}}$ & $66.20^{c}$ & $23.40^{\mathrm{a}}$ & $35.30^{\mathrm{a}}$ & $18.20^{\mathrm{abc}}$ & $385.0^{\mathrm{a}}$ & $0.19^{\mathrm{a}}$ & $5.20^{\mathrm{e}}$ & $6.60^{c}$ \\
\hline \multirow[t]{3}{*}{ M1 } & 1 day & $32.17^{b}$ & $67.33^{\mathrm{b}}$ & $25.13^{\mathrm{a}}$ & $40.60^{\mathrm{a}}$ & $18.83^{\mathrm{a}}$ & $124.0^{\mathrm{d}}$ & $0.08^{\mathrm{d}}$ & $6.10^{\mathrm{bc}}$ & $7.80^{\mathrm{a}}$ \\
\hline & 3 days & $31.70^{\mathrm{b}}$ & $67.57^{b}$ & $24.93^{\mathrm{a}}$ & $40.07^{\mathrm{a}}$ & $18.57^{\mathrm{ab}}$ & $117.0^{\mathrm{e}}$ & $0.06^{\mathrm{e}}$ & $6.00^{\mathrm{bcd}}$ & $6.50^{\mathrm{c}}$ \\
\hline & 7 days & $31.23^{b}$ & $67.77^{b}$ & $24.73^{\mathrm{a}}$ & $39.67^{\mathrm{a}}$ & $18.30^{\mathrm{abc}}$ & $106.0^{f}$ & $0.06^{\mathrm{e}}$ & $5.50^{\mathrm{de}}$ & $5.80^{\mathrm{d}}$ \\
\hline \multirow[t]{3}{*}{ M2 } & 1 day & $30.83^{b}$ & $68.97^{b}$ & $24.17^{\mathrm{a}}$ & $35.83^{\mathrm{a}}$ & $18.23^{\mathrm{abc}}$ & $226.0^{b}$ & $0.13^{b}$ & $6.90^{\mathrm{a}}$ & $7.17^{b}$ \\
\hline & 3 days & $30.47^{b}$ & $68.17^{b}$ & $23.93^{\mathrm{a}}$ & $35.50^{\mathrm{a}}$ & $18.03^{b c}$ & $226.0^{b}$ & $0.13^{b}$ & $6.40^{\mathrm{ab}}$ & $6.60^{c}$ \\
\hline & 7 days & $30.30^{b}$ & $68.77^{b}$ & $23.70^{\mathrm{a}}$ & $35.17^{\mathrm{a}}$ & $17.67^{\mathrm{c}}$ & $224.0^{b}$ & $0.13^{b}$ & $6.10^{\mathrm{bc}}$ & $6.30^{c}$ \\
\hline \multirow[t]{3}{*}{ M3 } & 1 day & $29.67^{b}$ & $74.17^{\mathrm{a}}$ & $21.10^{\mathrm{a}}$ & $34.07^{\mathrm{a}}$ & $18.03^{\mathrm{bc}}$ & $189.0^{c}$ & $0.11^{\mathrm{c}}$ & $6.50^{\mathrm{ab}}$ & $6.30^{c}$ \\
\hline & 3 days & $29.40^{b}$ & $74.33^{\mathrm{a}}$ & $20.83^{\mathrm{a}}$ & $33.73^{\mathrm{a}}$ & $17.87^{\mathrm{c}}$ & $122.0^{\mathrm{de}}$ & $0.08^{\mathrm{d}}$ & $5.70^{\text {cde }}$ & $4.60^{\mathrm{e}}$ \\
\hline & 7 days & $29.13^{b}$ & $74.50^{\mathrm{a}}$ & $20.57^{\mathrm{a}}$ & $33.40^{\mathrm{a}}$ & $17.70^{\mathrm{c}}$ & $65.0^{\mathrm{g}}$ & $0.03^{f}$ & $5.30^{\mathrm{e}}$ & $3.90^{f}$ \\
\hline \pm SEM & & 2.34 & 1.17 & 1.75 & 2.42 & 0.20 & 2.22 & 0.002 & 0.18 & 0.12 \\
\hline
\end{tabular}

Table-4: Effect of Lindane on Rabbit Haematology

\begin{tabular}{|c|c|c|c|c|c|}
\hline \multirow[t]{2}{*}{ Parameters } & \multicolumn{4}{|c|}{ Injected volume (ml) } & \multirow[t]{2}{*}{ \pm SEM } \\
\hline & $\mathbf{0}$ & 0.38 & 0.75 & 1.5 & \\
\hline White blood cell $\left(\mathrm{x} 10^{3} \mu \mathrm{l}\right)$ & $6.10^{\mathrm{a}}$ & $4.07^{b}$ & $2.63^{\mathrm{bc}}$ & $2.51^{\mathrm{c}}$ & 0.51 \\
\hline Lymphocytes $\left(\times 10^{3} \mu \mathrm{l}\right)$ & $5.30^{\mathrm{a}}$ & $1.71^{b}$ & $2.08^{b}$ & $2.62^{b}$ & 0.32 \\
\hline Monocytes $\left(\times 10^{3} \mu 1\right)$ & $0.40^{\mathrm{c}}$ & $0.43^{\mathrm{b}}$ & $0.48^{\mathrm{a}}$ & $0.49^{\mathrm{a}}$ & 0.06 \\
\hline $\operatorname{Gr}\left(\times 10^{3} \mu \mathrm{l}\right)$ & $0.60^{b}$ & $0.61^{b}$ & $0.62^{b}$ & $0.67^{\mathrm{a}}$ & 0.06 \\
\hline Lymphocytes (\%) & $83.40^{\mathrm{a}}$ & $82.73^{\mathrm{a}}$ & $75.43^{b}$ & $70.40^{b}$ & 2.52 \\
\hline Monocytes (\%) & $7.10^{\mathrm{c}}$ & $7.37^{\mathrm{c}}$ & $10.03^{\mathrm{b}}$ & $11.97^{\mathrm{a}}$ & 0.83 \\
\hline $\operatorname{Gr}(\%)$ & $9.50^{c}$ & $12.18^{\mathrm{b}}$ & $14.48^{\mathrm{b}}$ & $18.13^{\mathrm{a}}$ & 1.33 \\
\hline Red blood cell $\left(\times 10^{-6} \mu \mathrm{l}\right)$ & $6.14^{\mathrm{a}}$ & $5.82^{\mathrm{a}}$ & $5.57^{b}$ & $5.00^{\mathrm{c}}$ & 0.19 \\
\hline Heamoglobin $(\mathrm{g} / \mathrm{dL})$ & $14.40^{\mathrm{a}}$ & $13.40^{\mathrm{a}}$ & $13.36^{\mathrm{a}}$ & $13.30^{\mathrm{a}}$ & 0.57 \\
\hline $\operatorname{HCT}(\%)$ & $40.70^{\mathrm{a}}$ & $35.60^{\mathrm{b}}$ & $34.67^{b}$ & $34.17^{b}$ & 1.92 \\
\hline Mean corpuscular volume (fl) & $66.20^{\mathrm{b}}$ & $67.73^{\mathrm{a}}$ & $68.73^{\mathrm{a}}$ & $69.27^{\mathrm{a}}$ & 0.90 \\
\hline Mean corpuscular haemoglobin (pg) & $23.40^{\mathrm{a}}$ & $23.37^{\mathrm{a}}$ & $23.30^{\mathrm{a}}$ & $23.17^{\mathrm{a}}$ & 0.16 \\
\hline Mean corpuscular heamoglobin concentration $(\mathrm{g} / \mathrm{dl})$ & $35.30^{\mathrm{c}}$ & $40.37^{\mathrm{b}}$ & $43.60^{\mathrm{ab}}$ & $45.57^{\mathrm{a}}$ & 2.05 \\
\hline RDW (\%) & $18.20^{\mathrm{a}}$ & $17.60^{\mathrm{a}}$ & $17.47^{\mathrm{a}}$ & $17.77^{\mathrm{a}}$ & 2.91 \\
\hline Platelet count $\left(\mathrm{x} 10^{3} \mu \mathrm{l}\right)$ & $358.0^{\mathrm{b}}$ & $269.0^{\mathrm{b}}$ & $231.7^{\mathrm{a}}$ & $238.3^{\mathrm{a}}$ & 60.8 \\
\hline PCT $(\%)$ & $0.19^{\mathrm{a}}$ & $0.17^{\mathrm{a}}$ & $0.11^{\mathrm{b}}$ & $0.08^{\mathrm{b}}$ & 0.02 \\
\hline MPV (fl) & $5.20^{\mathrm{a}}$ & $4.50^{\mathrm{a}}$ & $4.44^{\mathrm{a}}$ & $3.70^{\mathrm{ab}}$ & 0.41 \\
\hline PDW (fl) & $6.60^{\mathrm{a}}$ & $5.27^{\mathrm{ab}}$ & $5.03^{\mathrm{ab}}$ & $3.17^{b}$ & 0.71 \\
\hline
\end{tabular}

\footnotetext{
${ }^{a b c}=$ Means in a row with different superscripts are significantly different $(\mathrm{P}<0.05)$
} 
Table-5: Effect of Lindane on Exposure Periods

\begin{tabular}{|c|c|c|c|c|}
\hline \multirow[t]{2}{*}{ Parameters } & \multicolumn{3}{|c|}{ Exposure Time } & \multirow[t]{2}{*}{ \pm SEM } \\
\hline & 1 day & 3 days & 7 days & \\
\hline White blood cell $\left(\times 10^{3} \mu 1\right)$ & $3.90^{\mathrm{a}}$ & $3.74^{\mathrm{a}}$ & $3.84^{\mathrm{a}}$ & 0.44 \\
\hline Lymphocytes $\left(\mathrm{x} 10^{3} \mu \mathrm{l}\right)$ & $2.96^{\mathrm{a}}$ & $2.97^{\mathrm{a}}$ & $2.86^{\mathrm{a}}$ & 0.28 \\
\hline Monocytes $\left(\mathrm{x} 10^{3} \mu \mathrm{l}\right)$ & $0.33^{\mathrm{a}}$ & $0.33^{\mathrm{a}}$ & $0.33^{\mathrm{a}}$ & 0.05 \\
\hline $\operatorname{Gr}\left(\mathrm{x} 10^{3} \mu \mathrm{l}\right)$ & $0.43^{\mathrm{a}}$ & $0.43^{\mathrm{a}}$ & $0.42^{\mathrm{a}}$ & 0.06 \\
\hline Lymphocytes (\%) & $77.99^{\mathrm{a}}$ & $78.54^{\mathrm{a}}$ & $77.44^{\mathrm{a}}$ & 2.19 \\
\hline Monocytes (\%) & $9.12^{\mathrm{a}}$ & $9.20^{\mathrm{a}}$ & $9.03^{\mathrm{a}}$ & 0.72 \\
\hline $\operatorname{Gr}(\%)$ & $13.56^{\mathrm{a}}$ & $13.48^{\mathrm{a}}$ & $13.68^{\mathrm{a}}$ & 1.16 \\
\hline Red blood cell $\left(\times 10^{-6} \mu 1\right)$ & $5.63^{\mathrm{a}}$ & $5.61^{\mathrm{a}}$ & $5.67^{\mathrm{a}}$ & 0.16 \\
\hline Heamoglobin (g/dL) & $13.57^{\mathrm{a}}$ & $13.41^{\mathrm{a}}$ & $13.64^{\mathrm{a}}$ & 0.49 \\
\hline $\operatorname{HCT}(\%)$ & $36.28^{\mathrm{a}}$ & $36.34^{\mathrm{a}}$ & $36.23^{\mathrm{a}}$ & 1.67 \\
\hline Mean corpuscular volume (fl) & $69.18^{\mathrm{a}}$ & $69.21^{\mathrm{a}}$ & $69.48^{\mathrm{a}}$ & 0.78 \\
\hline Mean corpuscular haemoglobin $(\mathrm{pg})$ & $24.31^{\mathrm{a}}$ & $24.28^{\mathrm{a}}$ & $24.34^{\mathrm{a}}$ & 1.0 \\
\hline Mean corpuscular heamoglobin concentration(g/dl) & $41.21^{\mathrm{a}}$ & $41.22^{\mathrm{a}}$ & $41.19^{\mathrm{a}}$ & 1.78 \\
\hline RDW (\%) & $20.76^{\mathrm{a}}$ & $20.84^{\mathrm{a}}$ & $20.68^{\mathrm{a}}$ & 2.52 \\
\hline Platelet count $\left(\times 10^{3} \mu 1\right)$ & $406.0^{\mathrm{a}}$ & $410.7^{\mathrm{a}}$ & $401.3^{\mathrm{a}}$ & 52.7 \\
\hline PCT $(\%)$ & $0.16^{\mathrm{a}}$ & $0.16^{\mathrm{a}}$ & $0.16^{\mathrm{a}}$ & 0.02 \\
\hline MPV (fl) & $4.46^{\mathrm{a}}$ & $4.50^{\mathrm{a}}$ & $4.43^{\mathrm{a}}$ & 0.35 \\
\hline PDW (fl) & $5.02^{\mathrm{a}}$ & $4.97^{\mathrm{a}}$ & $5.07^{\mathrm{a}}$ & 0.62 \\
\hline
\end{tabular}

Table-6: Effect of Lindane on Interaction (injected dose $x$ exposure periods)

\begin{tabular}{|l|l|l|l|l|l|l|l|l|l|l|}
\hline Concentration & $\begin{array}{l}\text { Exposure } \\
\text { Time }\end{array}$ & \multicolumn{9}{|c|}{ Parameters } \\
\hline & & WBC & LYM & MON & GR & $\begin{array}{c}\text { LYM } \\
(\%)\end{array}$ & $\begin{array}{c}\text { MON } \\
(\%)\end{array}$ & GR & RBC & HEA \\
\hline M & 0 hour & $6.10^{\mathrm{a}}$ & $5.30^{\mathrm{a}}$ & $0.40^{\mathrm{abc}}$ & $0.60^{\mathrm{a}}$ & $83.40^{\mathrm{a}}$ & $7.10^{\mathrm{c}}$ & $9.50^{\mathrm{b}}$ & $6.14^{\mathrm{a}}$ & $14.40^{\mathrm{a}}$ \\
\hline M1 & 1 day & $4.17^{\mathrm{ab}}$ & $2.73^{\mathrm{b}}$ & $0.47^{\mathrm{ab}}$ & $0.53^{\mathrm{a}}$ & $82.73^{\mathrm{a}}$ & $11.97^{\mathrm{ab}}$ & $18.13^{\mathrm{a}}$ & $5.79^{\mathrm{ab}}$ & $13.47^{\mathrm{a}}$ \\
\hline & 3 days & $4.03^{\mathrm{ab}}$ & $2.77^{\mathrm{b}}$ & $0.47^{\mathrm{ab}}$ & $0.57^{\mathrm{a}}$ & $83.27^{\mathrm{a}}$ & $12.13^{\mathrm{a}}$ & $17.73^{\mathrm{a}}$ & $5.64^{\mathrm{ab}}$ & $13.17^{\mathrm{a}}$ \\
\hline & 7 days & $4.00^{\mathrm{ab}}$ & $2.37^{\mathrm{b}}$ & $0.53^{\mathrm{a}}$ & $0.50^{\mathrm{a}}$ & $82.20^{\mathrm{a}}$ & $11.80^{\mathrm{abc}}$ & $18.53^{\mathrm{a}}$ & $6.04^{\mathrm{ab}}$ & $13.43^{\mathrm{a}}$ \\
\hline M2 & 1 day & $2.80^{\mathrm{b}}$ & $2.13^{\mathrm{b}}$ & $0.30^{\mathrm{abc}}$ & $0.27^{\mathrm{a}}$ & $75.43^{\mathrm{a}}$ & $10.03^{\mathrm{abc}}$ & $14.43^{\mathrm{ab}}$ & $5.57^{\mathrm{ab}}$ & $13.00^{\mathrm{a}}$ \\
\hline & 3 days & $2.37^{\mathrm{b}}$ & $2.10^{\mathrm{b}}$ & $0.33^{\mathrm{abc}}$ & $0.23^{\mathrm{a}}$ & $76.20^{\mathrm{a}}$ & $10.10^{\mathrm{abc}}$ & $14.57^{\mathrm{ab}}$ & $5.65^{\mathrm{ab}}$ & $12.87^{\mathrm{a}}$ \\
\hline & 7 days & $2.37^{\mathrm{b}}$ & $2.00^{\mathrm{b}}$ & $0.27^{\mathrm{abc}}$ & $0.30^{\mathrm{a}}$ & $74.67^{\mathrm{a}}$ & $9.97^{\mathrm{acc}}$ & $14.43^{\mathrm{ab}}$ & $5.50^{\mathrm{ab}}$ & $13.13^{\mathrm{a}}$ \\
\hline M3 & 1 day & $2.53^{\mathrm{b}}$ & $1.67^{\mathrm{b}}$ & $0.17^{\mathrm{bc}}$ & $0.33^{\mathrm{a}}$ & $70.40^{\mathrm{a}}$ & $7.37^{\mathrm{abc}}$ & $12.17^{\mathrm{ab}}$ & $5.00^{\mathrm{b}}$ & $13.40^{\mathrm{a}}$ \\
\hline & 3 days & $2.47^{\mathrm{b}}$ & $1.70^{\mathrm{b}}$ & $0.13^{\mathrm{c}}$ & $0.33^{\mathrm{a}}$ & $71.30^{\mathrm{a}}$ & $7.60^{\mathrm{abc}}$ & $12.13^{\mathrm{ab}}$ & $5.02^{\mathrm{b}}$ & $13.20^{\mathrm{a}}$ \\
\hline & 7 days & $2.90^{\mathrm{b}}$ & $1.77^{\mathrm{b}}$ & $0.13^{\mathrm{c}}$ & $0.27^{\mathrm{a}}$ & $69.50^{\mathrm{a}}$ & $7.13^{\mathrm{c}}$ & $12.23^{\mathrm{ab}}$ & $4.98^{\mathrm{b}}$ & $13.60^{\mathrm{a}}$ \\
\hline & & 0.88 & 0.56 & 0.09 & 0.11 & 4.37 & 1.43 & 2.31 & 0.32 & 0.98 \\
\hline
\end{tabular}

Table-6: Continued

\begin{tabular}{|c|c|c|c|c|c|c|c|c|c|c|}
\hline \multirow[t]{2}{*}{ Concentration } & \multirow{2}{*}{$\begin{array}{l}\text { Exposure } \\
\text { Time }\end{array}$} & \multicolumn{9}{|c|}{ Parameters } \\
\hline & & HCT & MCV & МСH & МСНС & RDW & PC & PCT & MPV & PDW \\
\hline $\mathrm{M}$ & 0 hour & $\begin{array}{c}40.70 \\
\mathrm{a}\end{array}$ & $66.20^{\mathrm{b}}$ & $23.40^{\mathrm{a}}$ & $35.30^{\mathrm{a}}$ & $18.20^{\mathrm{a}}$ & $385.0^{\mathrm{a}}$ & $0.19^{\mathrm{a}}$ & $5.20^{\mathrm{a}}$ & $6.60^{\mathrm{a}}$ \\
\hline \multirow[t]{3}{*}{ M1 } & 1 day & $35.60^{\mathrm{a}}$ & $67.63^{\mathrm{a}}$ & $23.17^{\mathrm{a}}$ & $40.37^{\mathrm{a}}$ & $17.60^{\mathrm{a}}$ & $438.3^{\mathrm{a}}$ & $0.19^{\mathrm{a}}$ & $4.50^{\mathrm{a}}$ & $5.03^{\mathrm{a}}$ \\
\hline & 3 days & $35.80^{\mathrm{a}}$ & $67.67^{\mathrm{a}}$ & $23.20^{\mathrm{a}}$ & $39.83^{\mathrm{a}}$ & $17.73^{\mathrm{a}}$ & $449.3^{\mathrm{a}}$ & $0.18^{\mathrm{a}}$ & $4.57^{\mathrm{a}}$ & $5.00^{\mathrm{a}}$ \\
\hline & 7 days & $35.40^{\mathrm{a}}$ & $67.83^{\mathrm{a}}$ & $23.13^{\mathrm{a}}$ & $40.90^{\mathrm{a}}$ & $17.47^{\mathrm{a}}$ & $427.3^{\mathrm{a}}$ & $0.19^{\mathrm{a}}$ & $4.43^{\mathrm{a}}$ & $5.07^{\mathrm{a}}$ \\
\hline \multirow[t]{3}{*}{ M2 } & 1 day & $34.17^{\mathrm{a}}$ & $68.27^{\mathrm{a}}$ & $23.37^{\mathrm{a}}$ & $43.60^{\mathrm{a}}$ & $29.77^{\mathrm{a}}$ & $369.0^{\mathrm{a}}$ & $0.08^{\mathrm{a}}$ & $3.70^{\mathrm{a}}$ & $3.17^{\mathrm{a}}$ \\
\hline & 3 days & $34.17^{\mathrm{a}}$ & $68.23^{\mathrm{a}}$ & $23.27^{\mathrm{a}}$ & $43.80^{\mathrm{a}}$ & $29.77^{\mathrm{a}}$ & $377.0^{\mathrm{a}}$ & $0.07^{\mathrm{a}}$ & $3.83^{\mathrm{a}}$ & $3.10^{\mathrm{a}}$ \\
\hline & 7 days & $34.17^{\mathrm{a}}$ & $68.30^{\mathrm{a}}$ & $23.47^{\mathrm{a}}$ & $43.40^{\mathrm{a}}$ & $29.77^{\mathrm{a}}$ & $361.0^{\mathrm{a}}$ & $0.08^{\mathrm{a}}$ & $3.57^{\mathrm{a}}$ & $3.23^{\mathrm{a}}$ \\
\hline \multirow[t]{3}{*}{ M3 } & 1 day & $34.67^{\mathrm{a}}$ & $69.70^{\mathrm{a}}$ & $27.30^{\mathrm{a}}$ & $45.57^{\mathrm{a}}$ & $17.47^{\mathrm{a}}$ & $431.7^{\mathrm{a}}$ & $0.17^{\mathrm{a}}$ & $4.43^{\mathrm{a}}$ & $5.27^{\mathrm{a}}$ \\
\hline & 3 days & $34.70^{\mathrm{a}}$ & $69.73^{\mathrm{a}}$ & $27.23^{\mathrm{a}}$ & $45.97^{\mathrm{a}}$ & $17.67^{\mathrm{a}}$ & $431.3^{\mathrm{a}}$ & $0.18^{\mathrm{a}}$ & $4.40^{\mathrm{a}}$ & $5.17^{\mathrm{a}}$ \\
\hline & 7 days & $34.63^{\mathrm{a}}$ & $69.87^{\mathrm{a}}$ & $27.37^{\mathrm{a}}$ & $45.17^{\mathrm{a}}$ & $17.27^{\mathrm{a}}$ & $432.0^{\mathrm{a}}$ & $0.17^{\mathrm{a}}$ & $4.50^{\mathrm{a}}$ & $5.37^{\mathrm{a}}$ \\
\hline \pm SEM & & 3.33 & 1.56 & 2.01 & 3.55 & 5.04 & 105.4 & 0.04 & 0.70 & 1.23 \\
\hline
\end{tabular}


Table-7: Effect of Endosulfan on Rabbit Haematology

\begin{tabular}{|c|c|c|c|c|c|}
\hline \multirow[t]{2}{*}{ Parameters } & \multicolumn{4}{|c|}{ Injected Volume (ml) } & \multirow[t]{2}{*}{ \pm SEM } \\
\hline & Control & 0.18 & 0.36 & 0.72 & \\
\hline White blood cell $\left(\mathrm{x} 10^{3} \mu \mathrm{l}\right)$ & $6.10^{\mathrm{a}}$ & $4.16^{b}$ & $3.82^{\mathrm{bc}}$ & $3.50^{\mathrm{bc}}$ & 0.11 \\
\hline Lymphocytes $\left(\mathrm{x} 10^{3} \mu \mathrm{l}\right)$ & $6.11^{\mathrm{a}}$ & $6.05^{\mathrm{a}}$ & $6.01^{\mathrm{a}}$ & $5.30^{\mathrm{ab}}$ & 0.23 \\
\hline Monocytes $\left(\times 10^{3} \mu 1\right)$ & $0.40^{\mathrm{ab}}$ & $0.49^{\mathrm{a}}$ & $0.52^{\mathrm{a}}$ & $0.56^{\mathrm{a}}$ & 0.06 \\
\hline $\operatorname{Gr}\left(\times 10^{3} \mu \mathrm{l}\right)$ & $0.60^{\mathrm{ab}}$ & $0.50^{\mathrm{b}}$ & $0.74^{\mathrm{a}}$ & $0.37^{\mathrm{c}}$ & 0.05 \\
\hline Lymphocytes (\%) & $98.93^{\mathrm{a}}$ & $96.89^{\mathrm{ab}}$ & $92.70^{\mathrm{ab}}$ & $83.40^{\mathrm{c}}$ & 2.00 \\
\hline Monocytes (\%) & $7.10^{\mathrm{b}}$ & $10.85^{\mathrm{a}}$ & $10.92^{\mathrm{a}}$ & $11.13^{\mathrm{a}}$ & 0.35 \\
\hline $\operatorname{Gr}(\%)$ & $9.50^{b}$ & $15.84^{\mathrm{a}}$ & $16.03^{\mathrm{a}}$ & $16.22^{\mathrm{a}}$ & 2.60 \\
\hline Red blood cell $\left(\times 10^{-6} \mu \mathrm{l}\right)$ & $6.14^{\mathrm{a}}$ & $4.83^{b}$ & $4.78^{\mathrm{b}}$ & $4.59^{b}$ & 0.35 \\
\hline Heamoglobin $(\mathrm{g} / \mathrm{dL})$ & $14.40^{\mathrm{a}}$ & $10.88^{b}$ & $10.83^{\mathrm{b}}$ & $10.75^{b}$ & 0.37 \\
\hline $\operatorname{HCT}(\%)$ & $40.70^{\mathrm{a}}$ & $33.96^{b}$ & $32.36^{\mathrm{b}}$ & $30.06^{b}$ & 0.71 \\
\hline Mean corpuscular volume (fl) & $66.20^{\mathrm{a}}$ & $66.54^{\mathrm{a}}$ & $67.20^{\mathrm{a}}$ & $67.65^{\mathrm{a}}$ & 1.36 \\
\hline Mean corpuscular haemoglobin $(\mathrm{pg})$ & $23.40^{\mathrm{a}}$ & $21.34^{\mathrm{a}}$ & $21.18^{\mathrm{a}}$ & $20.74^{\mathrm{a}}$ & 0.47 \\
\hline Mean corpuscular heamoglobin concentration $(\mathrm{g} / \mathrm{dl})$ & $35.30^{\mathrm{a}}$ & $35.51^{\mathrm{a}}$ & $37.05^{\mathrm{a}}$ & $37.56^{\mathrm{a}}$ & 0.56 \\
\hline RDW $(\%)$ & $18.20^{\mathrm{a}}$ & $17.14^{\mathrm{ab}}$ & $16.86^{\mathrm{ab}}$ & $16.44^{\mathrm{ab}}$ & 0.18 \\
\hline Platelet count $\left(\times 10^{3} \mu\right)$ & $358.0^{\mathrm{a}}$ & $147.5^{\mathrm{b}}$ & $114.7^{\mathrm{bc}}$ & $94.3^{\mathrm{c}}$ & 22.6 \\
\hline PCT (\%) & $0.19^{\mathrm{a}}$ & $0.06^{\mathrm{b}}$ & $0.06^{\mathrm{b}}$ & $0.05^{\mathrm{b}}$ & 0.01 \\
\hline MPV (fl) & $5.20^{\mathrm{a}}$ & $5.12^{b}$ & $4.90^{\mathrm{bc}}$ & $4.35^{\mathrm{c}}$ & 0.18 \\
\hline PDW (fl) & $6.60^{\mathrm{a}}$ & $5.91^{b}$ & $5.48^{\mathrm{c}}$ & $5.32^{\mathrm{c}}$ & 0.18 \\
\hline
\end{tabular}

${ }^{a b c}=$ Means in a row with different superscripts are significantly different $(\mathrm{P}<0.05)$

Table-8: Effect of Endosulfan on Exposure Periods

\begin{tabular}{|c|c|c|c|}
\hline \multirow[t]{2}{*}{ Parameters } & \multicolumn{2}{|c|}{ Exposure Time } & \multirow[t]{2}{*}{ \pm SEM } \\
\hline & 1 day & 3 days & \\
\hline White blood cell $\left(\mathrm{x} 10^{3} \mu \mathrm{l}\right)$ & $4.47^{\mathrm{a}}$ & $4.31^{\mathrm{a}}$ & 0.15 \\
\hline Lymphocytes $\left(\mathrm{x} 10^{3} \mu \mathrm{l}\right)$ & $5.83^{\mathrm{a}}$ & $5.83^{\mathrm{a}}$ & 0.20 \\
\hline Monocytes $\left(\mathrm{x} 10^{3} \mu \mathrm{l}\right)$ & $0.50^{\mathrm{a}}$ & $0.50^{\mathrm{a}}$ & 0.05 \\
\hline $\mathrm{Gr}\left(\mathrm{x} 10^{3} \mu \mathrm{l}\right)$ & $0.50^{\mathrm{a}}$ & $0.48^{\mathrm{a}}$ & 0.24 \\
\hline Lymphocytes $(\%)$ & $58.96^{\mathrm{a}}$ & $58.37^{\mathrm{a}}$ & 7.93 \\
\hline Monocytes (\%) & $8.52^{\mathrm{a}}$ & $9.57^{\mathrm{a}}$ & 1.31 \\
\hline $\operatorname{Gr}(\%)$ & $31.73^{\mathrm{a}}$ & $31.49^{\mathrm{a}}$ & 6.35 \\
\hline Red blood cell $\left(\times 10^{-6} \mu \mathrm{l}\right)$ & $5.22^{\mathrm{a}}$ & $5.10^{\mathrm{a}}$ & 0.30 \\
\hline Heamoglobin $(\mathrm{g} / \mathrm{dL})$ & $11.75^{\mathrm{a}}$ & $11.74^{\mathrm{a}}$ & 0.32 \\
\hline $\operatorname{HCT}(\%)$ & $34.72^{\mathrm{a}}$ & $34.43^{\mathrm{a}}$ & 0.61 \\
\hline Mean corpuscular volume (fl) & $67.43^{\mathrm{a}}$ & $66.68^{\mathrm{a}}$ & 1.18 \\
\hline Mean corpuscular haemoglobin $(\mathrm{pg})$ & $22.15^{\mathrm{a}}$ & $21.57^{\mathrm{a}}$ & 0.41 \\
\hline Mean corpuscular heamoglobin concentration $(\mathrm{g} / \mathrm{dl})$ & $33.24^{\mathrm{a}}$ & $33.17^{\mathrm{a}}$ & 0.49 \\
\hline RDW $(\%)$ & $17.34^{\mathrm{a}}$ & $17.17^{\mathrm{a}}$ & 0.15 \\
\hline Platelet count $\left(\mathrm{x} 10^{3} \mu\right)$ & $188.5^{\mathrm{a}}$ & $188.51^{\mathrm{a}}$ & 0.15 \\
\hline PCT (\%) & $0.10^{\mathrm{a}}$ & $0.09^{\mathrm{a}}$ & 0.01 \\
\hline MPV (fl) & $6.22^{\mathrm{a}}$ & $6.07^{\mathrm{a}}$ & $6.00^{\mathrm{a}}$ \\
\hline PDW (fl) & $6.13^{\mathrm{a}}$ & $6.08^{\mathrm{a}}$ & $6.00^{\mathrm{a}}$ \\
\hline
\end{tabular}

Table-9: Effect of Endosulfan on Interaction (injected dose $x$ exposure periods)

\begin{tabular}{|c|c|c|c|c|c|c|c|c|c|c|}
\hline Concentration & Exposure Time & \multicolumn{9}{|c|}{ Parameters } \\
\hline & & WBC & LYM & MON & GR & LYM (\%) & MON (\%) & GR & RBC & HEA \\
\hline $\mathrm{M}$ & Ohours & 6.10 & 5.30 & 0.40 & 0.60 & 83.40 & 7.10 & 9.50 & 6.14 & 14.40 \\
\hline M1 & 1 day & 4.50 & 2.73 & 0.47 & 0.53 & 82.73 & 11.97 & 18.13 & 5.79 & 13.47 \\
\hline & 3 days & 4.16 & 2.77 & 0.47 & 0.57 & 83.27 & 12.13 & 17.73 & 5.64 & 13.17 \\
\hline M2 & 1 day & 2.80 & 2.13 & 0.30 & 0.27 & 75.43 & 10.03 & 14.43 & 5.57 & 13.00 \\
\hline & 3 days & 2.37 & 2.10 & 0.33 & 0.23 & 76.20 & 10.10 & 14.57 & 5.65 & 12.87 \\
\hline M3 & 1 day & 2.53 & 1.67 & 0.17 & 0.33 & 70.40 & 7.37 & 12.17 & 5.00 & 13.40 \\
\hline & 3 days & 2.47 & 1.70 & 0.13 & 0.33 & 71.30 & 7.60 & 12.13 & 5.02 & 13.20 \\
\hline$\pm \mathrm{SEM}$ & & 0.88 & 0.56 & 0.09 & 0.11 & 4.37 & 1.43 & 2.31 & 0.32 & 0.98 \\
\hline
\end{tabular}




\section{Biochemical assay}

Tables 10- 18 show OCPs toxicity effects on serum biochemical assay of exposed rabbit samples based on injected doses, exposure periods and interactions (dose and exposure periods). Compared to the non-OCPs treated rabbits (control samples), the OCPs treated rabbit samples increased significantly $(\mathrm{P}>0.05)$ in glucose $(85.25-90.03)$, creatinine (1.03 - 1.51), total bilirubin (5.28 - 5.66) and urea (39.61 - 41.57) counts while, albumin (4.99 - 6.03) and total protein (13.00 - 16.49) counts decreased significantly $(\mathrm{P}<0.05)$. The exposure periods $(1,3$ and 7 days) showed increases in serum glucose $(89.26$ - 90.46), creatine $(1.11$ - 1.25), total bilirubin (5.01 - 5.02), urea (39.25 - 41.42) counts and decreases in albumin $(6.05$ - 6.14) and total protein $(16.68$ - 16.80) counts but these were not significantly different $(\mathrm{P}>0.05)$. The interaction (dose $\mathrm{x}$ exposure periods) showed significant differences $(\mathrm{P}<0.05)$ in biochemical parameters with increase in concentration and exposure time.

Table-10: Effect of DDT on Rabbit Serum Biochemical

\begin{tabular}{|c|c|c|c|c|c|}
\hline Parameters & \multicolumn{4}{|c|}{ Injected Volume (ml) } & \\
\hline & Control & 0.38 & 0.75 & 1.5 & \pm SEM \\
\hline Glucose & $83.55^{b}$ & $85.25^{\mathrm{a}}$ & $88.31^{\mathrm{a}}$ & $89.92^{\mathrm{a}}$ & 15.04 \\
\hline Creatine & $0.65^{\mathrm{c}}$ & $1.03^{\mathrm{b}}$ & $1.36^{\mathrm{a}}$ & $1.50^{\mathrm{a}}$ & 0.09 \\
\hline T-bil & $4.12^{b}$ & $5.28^{\mathrm{a}}$ & $5.36^{\mathrm{a}}$ & $5.31^{\mathrm{a}}$ & 0.09 \\
\hline Urea & $36.75^{\mathrm{c}}$ & $39.61^{b}$ & $40.46^{\mathrm{a}}$ & $40.75^{\mathrm{a}}$ & 0.25 \\
\hline Albumin & $7.12^{\mathrm{a}}$ & $6.09^{\mathrm{b}}$ & $5.64^{\mathrm{c}}$ & $5.51^{\mathrm{c}}$ & 0.14 \\
\hline Total Protein & $18.45^{\mathrm{a}}$ & $16.49^{b}$ & $16.03^{\mathrm{c}}$ & $16.01^{\mathrm{c}}$ & 0.18 \\
\hline
\end{tabular}

${ }^{a b c}=$ Means in a row with different superscripts are significantly different $(\mathrm{P}<0.05)$

Table-11: Effect of DDT on Serum Biochemical with respect to Exposure Periods

\begin{tabular}{|l|l|l|l|l|}
\hline Parameters & \multicolumn{3}{|c|}{ Exposure Time } & 土 SEM \\
\hline & 1 day & 3 days & 7 days & \\
\hline Glucose & $89.26^{\mathrm{a}}$ & $89.28^{\mathrm{a}}$ & $90.46^{\mathrm{a}}$ & 13.02 \\
\hline Creatine & $1.11^{\mathrm{a}}$ & $1.13^{\mathrm{a}}$ & $1.15^{\mathrm{a}}$ & 0.08 \\
\hline T-bilirubin & $5.01^{\mathrm{a}}$ & $5.02^{\mathrm{a}}$ & $5.02^{\mathrm{a}}$ & 0.09 \\
\hline Urea & $39.25^{\mathrm{a}}$ & $39.39^{\mathrm{a}}$ & $39.74^{\mathrm{a}}$ & 0.22 \\
\hline Albumin & $6.14^{\mathrm{a}}$ & $6.08^{\mathrm{a}}$ & $6.05^{\mathrm{a}}$ & 0.12 \\
\hline Total Protein & $16.80^{\mathrm{a}}$ & $16.76^{\mathrm{a}}$ & $16.68^{\mathrm{a}}$ & 0.15 \\
\hline
\end{tabular}

${ }^{\mathrm{a}}=$ Means in a row with the similar superscripts are not significantly different $(\mathrm{P}>0$.

Table-12: DDT Effects on Serum Biochemical with Respect to Interactions (injected dose $x$ exposure period)

\begin{tabular}{|c|c|c|c|c|c|c|c|}
\hline Concentration & Exposure Time & \multicolumn{6}{|c|}{ Parameters } \\
\hline & & Glucose & Creatine & Total bilirubin & Urea & Albumin & Total Protein \\
\hline M & 0 hour & $83.39^{\mathrm{c}}$ & $0.68^{\mathrm{d}}$ & $4.13^{\mathrm{c}}$ & $37.64^{\mathrm{c}}$ & $7.13^{\mathrm{a}}$ & $18.73^{\mathrm{a}}$ \\
\hline M1 & 1 day & $85.20^{\mathrm{bc}}$ & $0.69^{\mathrm{d}}$ & $4.28^{\mathrm{b}}$ & $39.67^{\mathrm{c}}$ & $5.24^{\mathrm{b}}$ & $15.48^{\mathrm{b}}$ \\
\hline & 3 days & $88.48^{\mathrm{b}}$ & $1.19^{\mathrm{c}}$ & $4.33^{\mathrm{b}}$ & $39.92^{\mathrm{c}}$ & $5.14^{\mathrm{bc}}$ & $15.47^{\mathrm{b}}$ \\
\hline & 7 days & $91.10^{\mathrm{a}}$ & $1.43^{\mathrm{b}}$ & $5.26^{\mathrm{a}}$ & $40.81^{\mathrm{bc}}$ & $4.98^{\mathrm{c}}$ & $15.45^{\mathrm{b}}$ \\
\hline M2 & 1 day & $85.26^{\mathrm{bc}}$ & $1.09^{\mathrm{bc}}$ & $5.14^{\mathrm{ab}}$ & $41.50^{\mathrm{b}}$ & $5.09^{\mathrm{c}}$ & $13.76^{\mathrm{c}}$ \\
\hline & 3 days & $94.96^{\mathrm{a}}$ & $1.40^{\mathrm{b}}$ & $5.36^{\mathrm{a}}$ & $42.69^{\mathrm{b}}$ & $4.99^{\mathrm{c}}$ & $13.68^{\mathrm{c}}$ \\
\hline & 7 days & $95.53^{\mathrm{a}}$ & $1.57^{\mathrm{a}}$ & $5.38^{\mathrm{a}}$ & $48.19^{\mathrm{a}}$ & $4.19^{\mathrm{b}}$ & $13.33^{\mathrm{c}}$ \\
\hline & 1 day & $86.20^{\mathrm{b}}$ & $1.28^{\mathrm{bc}}$ & $5.51^{\mathrm{a}}$ & $43.25^{\mathrm{ab}}$ & $5.14^{\mathrm{bc}}$ & $13.14^{\mathrm{c}}$ \\
\hline & 3 days & $97.74^{\mathrm{a}}$ & $1.47^{\mathrm{ab}}$ & $5.55^{\mathrm{a}}$ & $43.87^{\mathrm{ab}}$ & $5.09^{\mathrm{c}}$ & $13.02^{\mathrm{c}}$ \\
\hline & 7 days & $98.09^{\mathrm{a}}$ & $1.59^{\mathrm{a}}$ & $5.93^{\mathrm{a}}$ & $48.25^{\mathrm{a}}$ & $4.94^{\mathrm{c}}$ & $12.88^{\mathrm{d}}$ \\
\hline
\end{tabular}

Table-13: Effect of Lindane on Rabbit Serum Biochemical

\begin{tabular}{|c|c|c|c|c|c|}
\hline Parameters & \multicolumn{4}{|c|}{ Injected Volume (ml) } & \pm SEM \\
\hline & Control & 0.38 & 0.75 & 1.5 & \\
\hline Glucose (mmol/L) & $83.55^{\mathrm{c}}$ & $85.56^{b}$ & $87.54^{\mathrm{b}}$ & $89.03^{\mathrm{a}}$ & 0.32 \\
\hline Creatine (mmol/L) & $0.65^{\mathrm{c}}$ & $1.40^{\mathrm{b}}$ & $1.41^{\mathrm{b}}$ & $1.45^{\mathrm{a}}$ & 0.08 \\
\hline Total bilirubin $(\mu \mathrm{mol} / \mathrm{L})$ & $4.12^{\mathrm{c}}$ & $4.68^{b}$ & $5.59^{\mathrm{a}}$ & $5.66^{\mathrm{a}}$ & 0.08 \\
\hline Urea $(\mathrm{mmol} / \mathrm{L})$ & $36.75^{\mathrm{c}}$ & $40.13^{b}$ & $40.40^{\mathrm{a}}$ & $40.45^{\mathrm{a}}$ & 0.56 \\
\hline Albumin (g/dL) & $7.12^{\mathrm{a}}$ & $5.12^{\mathrm{b}}$ & $5.06^{\mathrm{b}}$ & $4.99^{c}$ & 0.27 \\
\hline Total Protein $(\mathrm{g} / \mathrm{dL})$ & $18.45^{\mathrm{a}}$ & $15.47^{\mathrm{b}}$ & $13.59^{\mathrm{c}}$ & $13.00^{\mathrm{c}}$ & 0.32 \\
\hline
\end{tabular}


Table-14: Effect of Lindane on Serum Biochemical with respect to Exposure Periods

\begin{tabular}{|l|l|l|l|l|}
\hline Parameters & \multicolumn{3}{|c|}{ Exposure Time } & SEM \\
\hline & 1 day & 3 days & 7 days & \\
\hline Glucose & $70.46^{\mathrm{a}}$ & $72.47^{\mathrm{a}}$ & $77.60^{\mathrm{a}}$ & 6.71 \\
\hline Creatine & $1.09^{\mathrm{a}}$ & $1.12^{\mathrm{a}}$ & $1.25^{\mathrm{a}}$ & 0.07 \\
\hline Total bilirubin & $4.76^{\mathrm{a}}$ & $4.84^{\mathrm{a}}$ & $4.97^{\mathrm{a}}$ & 0.10 \\
\hline Urea & $40.06^{\mathrm{a}}$ & $40.81^{\mathrm{a}}$ & $41.42^{\mathrm{a}}$ & 0.47 \\
\hline Albumin & $5.61^{\mathrm{a}}$ & $5.57^{\mathrm{a}}$ & $5.53^{\mathrm{a}}$ & 0.23 \\
\hline Total Protein & $15.28^{\mathrm{a}}$ & $15.10^{\mathrm{a}}$ & $15.00^{\mathrm{a}}$ & 0.27 \\
\hline
\end{tabular}

${ }^{\mathrm{a}}=$ Means in a row with similar superscripts are not significantly different $(\mathrm{P}>0.05)$

Table-15: Effect of Lindane on Serum Biochemical Interactions

\begin{tabular}{|l|l|c|c|c|c|c|c|}
\hline Concentration & Exposure & & \multicolumn{5}{|c|}{ Parameters } \\
\hline & & Glucose & Creatine & Total bilirubin & Urea & Albumin & Total Protein \\
\hline M & 0 hours & $83.39^{\mathrm{c}}$ & $0.68^{\mathrm{d}}$ & $4.13^{\mathrm{c}}$ & $37.64^{\mathrm{c}}$ & $7.13^{\mathrm{a}}$ & $18.73^{\mathrm{a}}$ \\
\hline M1 & 1 day & $84.98^{\mathrm{c}}$ & $0.69^{\mathrm{d}}$ & $4.28^{\mathrm{c}}$ & $39.67^{\mathrm{c}}$ & $5.24^{\mathrm{b}}$ & $15.48^{\mathrm{b}}$ \\
\hline & 3 days & $87.65^{\mathrm{bc}}$ & $1.00^{\mathrm{c}}$ & $4.33^{\mathrm{c}}$ & $39.92^{\mathrm{c}}$ & $5.14^{\mathrm{bc}}$ & $15.47^{\mathrm{b}}$ \\
\hline & 7 days & $88.56^{\mathrm{bc}}$ & $1.33^{\mathrm{bc}}$ & $4.39^{\mathrm{c}}$ & $40.81^{\mathrm{c}}$ & $4.98^{\mathrm{cd}}$ & $15.45^{\mathrm{b}}$ \\
\hline M2 & 1 day & $90.48^{\mathrm{b}}$ & $1.17^{\mathrm{bc}}$ & $5.14^{\mathrm{bc}}$ & $41.50^{\mathrm{b}}$ & $5.09^{\mathrm{c}}$ & $13.76^{\mathrm{c}}$ \\
\hline & 3 days & $92.22^{\mathrm{ab}}$ & $1.60^{\mathrm{a}}$ & $5.36^{\mathrm{bc}}$ & $42.69^{\mathrm{b}}$ & $4.99^{\mathrm{cd}}$ & $13.68^{\mathrm{c}}$ \\
\hline M3 & 7 days & $94.89^{\mathrm{a}}$ & $1.59^{\mathrm{a}}$ & $5.38^{\mathrm{bc}}$ & $48.99^{\mathrm{a}}$ & $4.91^{\mathrm{cd}}$ & $13.33^{\mathrm{c}}$ \\
\hline & 1 day & $91.55^{\mathrm{ab}}$ & $1.07^{\mathrm{c}}$ & $5.51^{\mathrm{b}}$ & $43.25^{\mathrm{b}}$ & $5.14^{\mathrm{bc}}$ & $13.14^{\mathrm{c}}$ \\
\hline & 3 days & $94.50^{\mathrm{a}}$ & $1.24^{\mathrm{bc}}$ & $5.55^{\mathrm{b}}$ & $43.87^{\mathrm{b}}$ & $5.09^{\mathrm{c}}$ & $13.00^{\mathrm{c}}$ \\
\hline SEM & 7 days & $94.64^{\mathrm{a}}$ & $1.40^{\mathrm{b}}$ & $5.93^{\mathrm{a}}$ & $46.25^{\mathrm{ab}}$ & $4.94^{\mathrm{cd}}$ & $12.88^{\mathrm{c}}$ \\
\hline
\end{tabular}

Table-16: Effect of Endosulfan on Rabbit Serum Biochemical

\begin{tabular}{|c|c|c|c|c|c|}
\hline Parameters & \multicolumn{4}{|c|}{ Injected Volume (ml) } & \pm SEM \\
\hline & Control & 0.18 & 0.36 & 0.72 & \\
\hline Glucose (mmol/L) & $83.55^{\mathrm{a}}$ & $89.54^{\mathrm{b}}$ & $89.59^{b}$ & $90.03^{b}$ & 0.32 \\
\hline Creatine $(\mathrm{mmol} / \mathrm{L})$ & $0.65^{\mathrm{c}}$ & $1.21^{\mathrm{b}}$ & $1.24^{\mathrm{b}}$ & $1.51^{\mathrm{a}}$ & 0.08 \\
\hline Total bilirubin $(\mu \mathrm{mol} / \mathrm{L})$ & $4.12^{\mathrm{c}}$ & $5.44^{\mathrm{b}}$ & $5.49^{\mathrm{b}}$ & $5.51^{\mathrm{a}}$ & 0.08 \\
\hline Urea $(\mathrm{mmol} / \mathrm{L})$ & $36.75^{\mathrm{c}}$ & $41.13^{b}$ & $41.40^{\mathrm{a}}$ & $41.57^{\mathrm{a}}$ & 0.56 \\
\hline Albumin $(\mathrm{g} / \mathrm{dL})$ & $7.12^{\mathrm{a}}$ & $5.21^{\mathrm{b}}$ & $5.16^{\mathrm{b}}$ & $4.73^{\mathrm{c}}$ & 0.27 \\
\hline Total Protein $(\mathrm{g} / \mathrm{dL})$ & $18.45^{\mathrm{a}}$ & $16.47^{b}$ & $14.19^{c}$ & $13.59^{\mathrm{c}}$ & 0.32 \\
\hline
\end{tabular}

Table-17: Effect of Endosulfan on Serum Biochemical with Respect to Exposure Periods

\begin{tabular}{|l|c|c|c|}
\hline Parameters & \multicolumn{2}{|c|}{ Exposure Time } & 土SEM \\
\hline Glucose & 1 day $^{\text {3 days }}$ & \\
\hline Creatine & $87.60^{\mathrm{a}}$ & $89.47^{\mathrm{a}}$ & 6.71 \\
\hline Total bilirubin & $4.09^{\mathrm{a}}$ & $1.12^{\mathrm{a}}$ & 0.07 \\
\hline Urea & $4.84^{\mathrm{a}}$ & 0.10 \\
\hline Albumin & $5.06^{\mathrm{a}}$ & $40.81^{\mathrm{a}}$ & 0.47 \\
\hline Total Protein & $15.10^{\mathrm{a}}$ & $15.57^{\mathrm{a}}$ & 0.23 \\
\hline
\end{tabular}

${ }^{\mathrm{a}}=$ Means in a row with the similar superscripts are not significantly different $(\mathrm{P}>0.05)$

Table-18: Endosulfan Effect on Serum Biochemical Interactions

\begin{tabular}{|l|l|c|c|c|c|c|c|}
\hline Concentration & Exposure & \multicolumn{6}{|c|}{ Parameters } \\
\hline & & Glucose & Creatine & Total bilirubin & Urea & Albumin & Total Protein \\
\hline M & 0 hours & $83.39^{\mathrm{c}}$ & $0.68^{\mathrm{d}}$ & $4.13^{\mathrm{c}}$ & $37.64^{\mathrm{c}}$ & $7.13^{\mathrm{a}}$ & $18.73^{\mathrm{a}}$ \\
\hline M1 & 1 day & $84.98^{\mathrm{c}}$ & $0.69^{\mathrm{d}}$ & $4.28^{\mathrm{b}}$ & $39.67^{\mathrm{b}}$ & $5.24^{\mathrm{b}}$ & $15.48^{\mathrm{b}}$ \\
\hline & 3 days & $87.65^{\mathrm{c}}$ & $1.00^{\mathrm{c}}$ & $4.33^{\mathrm{b}}$ & $39.92^{\mathrm{b}}$ & $5.14^{\mathrm{bc}}$ & $15.47^{\mathrm{b}}$ \\
\hline M2 & 1 day & $90.48^{\mathrm{b}}$ & $1.17^{\mathrm{bc}}$ & $5.14^{\mathrm{ab}}$ & $41.50^{\mathrm{ab}}$ & $5.09^{\mathrm{c}}$ & $13.76^{\mathrm{c}}$ \\
\hline & 3 days & $92.22^{\mathrm{ab}}$ & $1.60^{\mathrm{a}}$ & $5.36^{\mathrm{a}}$ & $42.69^{\mathrm{ab}}$ & $4.99^{\mathrm{c}}$ & $13.68^{\mathrm{c}}$ \\
\hline M3 & 1 day & $91.55^{\mathrm{ab}}$ & $1.07^{\mathrm{c}}$ & $5.51^{\mathrm{a}}$ & $43.25^{\mathrm{a}}$ & $5.14^{\mathrm{bc}}$ & $13.14^{\mathrm{c}}$ \\
\hline \multicolumn{2}{|c|}{} & $94.50^{\mathrm{a}}$ & $1.24^{\mathrm{b}}$ & $5.55^{\mathrm{a}}$ & $43.87^{\mathrm{a}}$ & $5.09^{\mathrm{c}}$ & $13.00^{\mathrm{c}}$ \\
\hline SEM & 3 days & 0.55 & 0.13 & 0.14 & 0.95 & 0.26 & 0.55 \\
\hline
\end{tabular}




\section{DISCUSSION}

The varied clinical signs exhibited by the OCPs (DDT, endosulfan and lindane) subcutaneously injected rabbits indicated their physical responses to OCPs toxicity and this agrees with Zorawar et al. [15] on OCPs exposure in rats affecting the central nervous system, causing hyper-excitable state in the brain possibly leading to convulsion, tremor, hyper-reflexia and ataxia. The significant deviations in blood parameter counts (haematology and serum biochemical) in the OCPs exposed rabbits compared to the non-OCPs exposed rabbits (control) indicated the immunological responses to OCPs (DDT, endosulfan and lindane) toxicity.

The WBC and differential WBC decrease counts, indicates a probable systemic damage of the rabbit's immune system due to acute stress and infections induced by toxicity and this is in line with Bigoniyaa et al. [16] that decrease in white blood cell (leucocytes) indicates the activation of the animal's defense mechanism against toxic invasion. Kartheek and David [17] stated that the variations in leucocytes indices indicate stress conditions arising from OCPs exposures in rabbits due to their inability to produce or release antibiotics that are major defensive agents to combat infections. The reduction in leucocytes production may result in immunosuppressive effects that could lead to situations of antiendomosis and haemodilution challenges in rabbit's immune system resulting in leucopenia, allergic conditions, anaphylactic shock and certain parasitism [18].

The decrease in the RBC (erythrocytes), haemoglobin and hematocrit counts were possibly due to inhibited red blood cells production, decrease in number of matured RBCs released into blood circulation and shortened life span of circulating erythrocytes [19]. This agrees with Jyostana et al. [20] that pesticides poisoning increases erythrocyte destruction as a result of impaired biosynthesis of haeme in the bone marrow resulting in lower levels of erythropoietin, haemoglobins and hematocrit destruction. According to Kartheek and David [17], OCPs exposure in rabbit demolishes RBC concentrations or erythropoietic mechanism and reduces haemoglobins and hematocrit counts resulting in heamolysis and haemorrhagic situations.

OCPs toxicity effects in the red blood cell indices (Mean Corpuscular volume [MCV], Mean Corpuscular heamoglobin $[\mathrm{MCH}]$, Mean Corpuscular heamoglobin concentration [MCHC] and Red cell distribution width [RDW]) counts suggest haemopoietic deficiencies that may subsequently lead to anaemic (normocytic, microcytic, macrocytic, hypochronic or normochromic) conditions in exposed rabbits [21].

The deviations in platelet (PCT, MPV and PDW) counts in the exposed rabbits may lead to possible platelet diseases and in line with Kanu et al. [22] may result in aplastic anemic conditions (thrombocytopenia) due to the inability of blood tissues to retract or cause clot retraction that aids blood coagulation.

Blood serum counts in the OCPs exposed rabbit's shows toxicant stress and the need for production of extra energy by the rabbits to combat such induced stress. In line with Ambali et al. [23], the increase in serum glucose counts may lead to possible glucose homeostasis conditions in exposed rabbits, inducing hyperglycemia through reduced insulin secretion, hepatic glucogenesis and glycogenolysis stimulation due to damage of the hepatic glycogenesis pathway resulting in disease conditions such as diabetes mellitus [24]. The increase in total bilirubin counts suggest conditions of hepatotoxicity and may indicate possible liver damage, in line with Uchendu et al. [25]. The increase in urea and creatine counts in the exposed rabbits indicates possible kidney impairment and nephrotoxicity, since serum urea and creatine counts are reliable indicators of kidney functionality and glomerular filtration damages [26]. The decrease in the serum total protein and albumin counts indicates a possible diagnostic symptoms of liver diseases [27] and in line with Khalifa et al. [28] the increase in proteolytic activity occasioned by OCPs toxicity causes change in protein and free amino acid metabolism synthesized in the liver which results in degradation and renal failures due to increased utilization of albumin in the production of antibodies and excretion of albumin (Albumiurea).

\section{CONCLUSION}

OCPs toxicity constitute real threat to public health considering the severe detrimental effects on the blood parameters (haematology and serum biochemical assay) of exposed rabbits, thereby compromising their immune system to varied health complications. There is the need for serious health concerns especially to avert the consumption of OCPs laden smoke-dried fishes, hence the relevant governmental agencies (inspectorate/quality assurance in the Department of the Federal and State Fisheries, Ministries of Health, Agriculture, NAFDAC and SON) should ensure strict enforcement of enacted laws that ban the use of organochlorine pesticides in food and should engage in the periodic check of smokedried fish quality sold in markets and retail outlets in Nigeria to guide against OCPs usages. 


\section{ACKNOWLEDGEMENT}

Special thanks to Tertiary Education Trust Fund for the grant which supported this work. (TETFUND/NRF2014

'Use of pesticides in food preservation in Nigeria and its implications').

\section{REFERENCES}

1. Kumolu-Johnson, C.A., \& Ndi, P.E. (2011). A Review on Post-Harvest Losses in Artisanal Fisheries of Some African Countries. Journal of Fisheries and Aquatic Science, 6(4), 365-378.

2. Igene, J.O., Abolagba, O.J., \& Ikeme, A.I. (1998). Use of pesticides on cured fish in Nigeria. Report and Proceedings of the Sixth FAO Expert Consultation on Fish Technology in Africa Kisumu, Kenya, 126 - 130.

3. Musa, U., Hati, S.S., Adamu, Y.I., \& Mustapha, A. (2010). Pesticides Residues in Smoked Fish Samples from North-Eastern Nigeria. Journal of Applied Sciences, 10(11), 975-980.

4. Abolagba, O.J., \& Nuntah, J.N. (2012). Effects of Three Pesticides Used In Fish Preservation on the Heamatological Indices of Rabbits Fed Varying Levels. Nigerian Journal of Agriculture, Food and Environment, 8(4), 46-50.

5. Akoto, O., Azuure, A.A., \& Adotey, K. D. (2016). Pesticide residues in water, sediment and fish from Tono Reservoir and their health risk implications. SpringerPlus, 5: 1849-1860.

6. Carvalho, F.P. (2017). Pesticides, Environment and Food Safety. Food and Energy Security, 6(2), 48 - 60.

7. Maurya, P.K., \& Malik, D.S. (2016). Accumulation and distribution of organochlorine and organophosphorus pesticide residues in water, sediments and fishes, Heteropneustis fossilis and Puntius ticto from Kali River, India. Journal of Toxicology and Environmental Health Sciences, 8(5), 30 - 40.

8. Salameh, R.P., Daldi, I., Brochard, P. \& Saleh, B.A. (2004). Pesticides in Lebanon: a knowledge, attitude and practice study. Environment Research, 94, 1 - 6.

9. Thompson, L.A., Darwish, W.S., Ikenaka, Y., Nakayama, S.M.M., Mizukawa, H. \& Ishizuka, M. (2017). Organochlorine pesticide contamination of foods in Africa: incidence and Public Health Significance. Journal of Veterinary Medical Sciences, 79(4), 751-764.

10. Ize-Iyamu, O.K., Asia, I.O., \& Egwakhide, P.A. (2007). Concentrations of residues from organochlorine pesticide in water and fish from some rivers in Edo State, Nigeria. International Journal of Adolescent Medicine and Health, 2(9), 237 - 241.

11. Adeyemi, D., Ukpo, G., Anyakora, C. and Unyimandu, J. (2008). Organochlorine pesticides residues in fish samples from Lagos Lagoon, Nigeria. American Journal of Environmental Science, 4, 649-653.

12. Abolagba, O.J., Igene, J.O. \& Usifoh, C.O. (2011). Studies of Pesticide Residues in Smoked Catfish (Clarias gariepinus) in Nigeria: Some Health Implications. Australian Journal of Basic and Applied Sciences, 5(5), $496-502$.

13. Venkatesan, R., Nagarajan, P. Rajaretnam, R.S., \& Majumdar, S.S. (2006). Haematologic and Serum biochemical values in aged female bonnet macaques (Macaca radiata) anesthetized with Ketamine hydrochlorine. Journal of the American Association for Laboratory Animal Science, 45(2), 45- 48.

14. Genstat. (2009). GenstatPC/Windows Vista Package Version 12.1. Laws Agricultural Trust, Rothamsted Experimental Station.

15. Zorawar, S., Jasminder, K., Ravneet, K., \& Swarndeep, S.H. (2016). Toxic Effects of Organochlorine Pesticides: A Review. American Journal of Bioscience, 4(3-1), 11-18.

16. Bigoniyaa, P., Sahu, T., \& Tiwari, V. (2015). Haematological and biochemical effects of sub-chronic artesunate exposure in rats. Toxicology Reports, 2, 280-288.

17. Kartheek, R.M., \& David, M. (2017). Modulations in Haematological Aspects of Wistar Rats Exposed to Sublethal Doses of Fipronil under Subchronic Duration. Journal of Pharmaceutical, Chemical and Biological Science, 5(3), 187-194.

18. Togun, V.A., Oseni, B.S.A., Ogundipe, J.A., Arewa, T.R., Hammed, A.A., Ajonijebu, D.C. \& Mustapha, F. (2007). Effects of chronic lead administration on the haematological parameters of rabbits. In: Proceedings of $41 \mathrm{st}$ Conference of the Agricultural Society of Nigeria, 341.

19. Mehra, B.L., Sharma, P., Kaushik, U., \& Joshi, S.C. (2014). Effect of Fytolan on Haematology and Serum Parameters of Male Albino Rats. International Journal of Pharma Research and Health Sciences, 2, 332 -338.

20. Jyostana, A.P., Arun, J.P., \& Sanjay, P.G. (2003). Biochemical effects of various pesticides on sprayers of grape gardens, Indian Journal of Clinical Biochemistry, 18, 16 - 22.

21. Goel, A., Danni, V., \& Dhawan, D.K. (2006). Role of zinc in mitigating the toxic effects of chlorpyrifos on hematological alterations and electron microscopic observations in rat blood. Biometals, 19, 483 - 492.

22. Kanu, K.C., Ijioma, S.N. \& Atiata, O. (2016). Haematological, Biochemical and Antioxidant Changes in Wistar Rats Exposed to Dichlorvos Based Insecticide Formulation Used in Southeast Nigeria. Toxics, 4(28), $1-8$.

23. Ambali, S.F., Shuaib, K., Edeh, R., Orieji, B.C., Shittu, M. \& Akande, M.G. (2011). Hyperglycemia induced by subchronic co-administration of chlorpyrifos and lead in Wistar rats: Role of pancreatic lipoperoxidation and alleviating effect of vitamin C. Biology and Medicine, 3, 6-14.

24. Mossa, A.H., \& Abbassy, M.A. (2012). Adverse Haematological and Biochemical Effects of Certain Formulated Insecticides in Male Rats. Journal of Environmental Toxicology, 6(4), 160 - 168. 
25. Uchendu, C., Ambali, S.F., Ayo, J.O., Esievo, K.A.N., Lasisi, I.O. \& Surakat, Y.L. (2011). Protective Effects of Acetyl-L-Carnitine on Subacute Chlorpyrifos induced Biochemical Changes in Wistar Rats. International Journal of Biological Chemistry, 5 (5), 300-313.

26. Heikal, T.M., Mossa, T.H., Marei, G.I.K., \& Rasoul, M.A.A. (2012). Cyromazine and Chlorpyrifos Induced Renal Toxicity in Rats: The Ameliorating Effects of Green Tea Extract. Journal Environmental Analytical Toxicology, 2(5), $146-152$

27. Mossa, A.H., Refaie, A.A., \& Ramadan, A. (2011). Effect of exposure to mixture of four organophosphate insecticides at no observed adverse effect level dose on rat liver: The protective role of vitamin C. Research Journal Environmental Toxicology, 5, 323-335.

28. Khalifa, F.K., Khalil, F.A., Barakat, H.A., \& Hassan M.M. (2011). Protective Role of Wheat Germ and Grape Seed Oils in Chlorpyrifos-Induced Oxidative Stress, Biochemical and Histological Alterations in Liver of Rats. Australian Journal of Basic and Applied Sciences, 5(10), 54 - 66. 